\title{
Construction of deep plastic concrete cut-off wall in upstream coffer dam of Punatsangchhu-I Hydropower Project, Bhutan
}

\author{
PK Gajbhiye \\ Geological Survey of India \\ Pune, India \\ pkgajbhiye@yahoo.com
}

\begin{abstract}
Several examples of leakage through abutments and foundation of dams have been witnessed world over, but with the advent of modern technology and innovative approach, such problems are being tackled successfully. The piping and internal erosion within thick overburden in river valley was a major geotechnical issue for upstream coffer dam of Punatsangchhu-1 hydropower project, Bhutan. The plastic concrete cut off wall as diaphragm was designed and successfully installed as best option to encounter the water leakage through the dam body up to acceptable level. The key to the success was proper planning, thorough geological investigations by exploration, safe design, good workmanship and remedial measures adopted during construction for risk reduction. This paper highlights about delineation of bed rock profile by exploration and successful construction of $132 \mathrm{~m}$ long and maximum $93 \mathrm{~m}$ deep plastic concrete cut off wall, which is one of its own kinds and deepest diaphragm wall in the geologically complex Himalayan terrain.
\end{abstract}

Keywords-abutment; foundation; coffer dam; plastic concrete; cut off wall; exploration

\section{INTRODUCTION}

The Punatsangchhu-1 hydropower project involves construction of $136 \mathrm{~m}$ high concrete gravity dam, $9.7 \mathrm{Km}$ long $\& 10 \mathrm{~m}$ diameter head race tunnel (HRT) to carry the water to underground power house for generation of $1200 \mathrm{MW}(6 \mathrm{x}$ $200 \mathrm{MW}$ ) of power. To facilitate the excavation of main dam, a $23 \mathrm{~m}$ high coffer dam with its top at El $1187 \mathrm{~m}$ was proposed across the river Punatsangchhu at $\pm 415 \mathrm{~m}$ upstream of main dam axis. Fig.1.shows a general lay out plan of the project.

The upstream coffer dam site was geologically mapped and investigated by drilling seven numbers of exploratory drill holes, to ascertain the bed rock profile and evaluate the rock mass condition. The surface geological mapping and bore hole data revealed the presence of thick colluvium material, consisting of small to big size rocky boulders set in silty and sandy matrix and $20-25 \mathrm{~m}$ wide zone of river borne material (RBM) below El 1125m. The RBM zone comprised sandy layers and well-polished pebbles of gneiss, quartzite and leucogranite representing a buried channel, contemplating an old course of the river.

Due to presence of thick colluvium underlain by deep buried channel, the deepest level of the bed rock in river bed was ascertained at $\mathrm{El} 1100 \mathrm{~m}$, i.e. about $87 \mathrm{~m}$ deep from top elevation of the coffer dam (El 1187m). The borehole drilling witnessed a complete water loss in all the boreholes indicating loose and permeable mass.

Considering thick overburden in river bed, the coffer dam was designed with a provision of raft foundation on the colluvium material itself by using composite of colcrete, rock fill mix and impervious clay. But the major geotechnical issue was apprehension of possible leakage of water through piping and erosion within loose and permeable overburden material lying below the proposed dam body thus hampering the progress and causing unnecessary risk.

A number of options were thought off, including jet grouting, curtain grouting and consolidation/permeation grouting and Cut-off Wall (COW) to strengthen the mass and restrict the leakage. Considering the high percentage and big size of the rock boulders, ultimately $1.2 \mathrm{~m}$ thick plastic concrete cut off wall in the center of dam body, extended up to the bed rock, was selected as best technical option to restrict the probable leakage of water to acceptable limit $(<1$ lugeon) and reduce the risk.

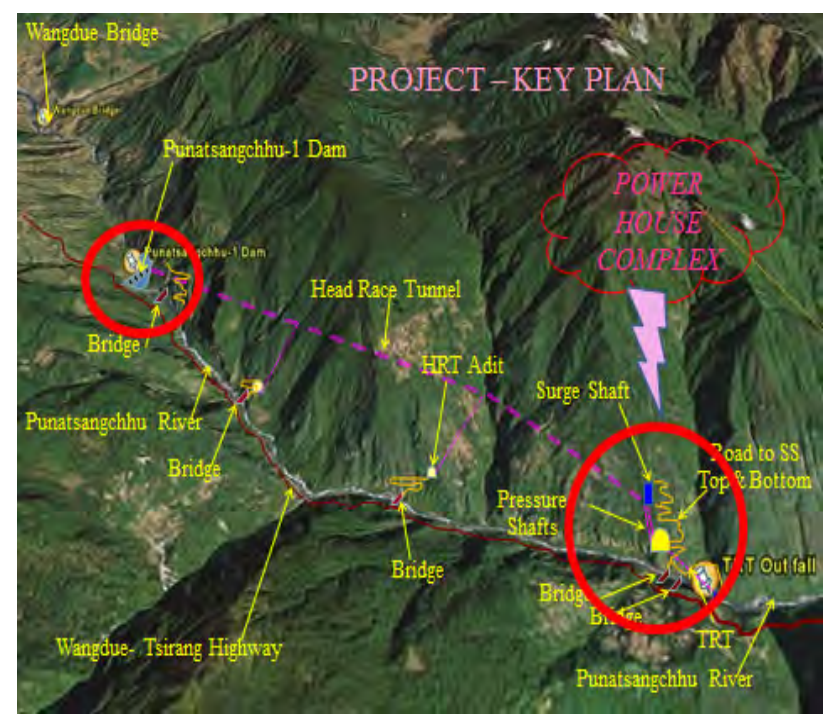

Fig.1.General Lay Out Plan of the Project 


\section{GeOlogical Set UP}

\section{A. Regional Geology}

Regionally the project area is located within a part of the Tethyan Belt of Bhutan Himalayas, which lies in the north of Main Central Thrust (MCT) and the rocks of Sure Formation of Thimphu Group of Precambrian age are exposed. The rocks of Thimphu Group in general are characterized by coarse grained quartzo-feldspathic, biotite-muscovite gneiss with bands of mica schist, quartzite and concordant veins of pegmatite, leucogranite and migmatites with minor bands of limestone/dolomites and metabasics. In addition, colluvial deposits derived from the country rock and river terraces formed on the right bank of Punatsangchhu River are also seen in the area. On the basis of study of aerial photographs three lineaments have been picked up in the area, which trends in i) $\mathrm{N}-\mathrm{S}$ ii) NW-SE and iii) NE-SW directions. The Punatsangchhu River probably flows along one of such sympathetic N-S trending lineament in the project area.

\section{B. Geology of the project area}

The bedrock exposed in the project area are represented by garnet bearing, foliated and jointed quartz-biotite gneiss and quartzo-feldspathic gneiss with bands of muscovite-biotite schist and veins/bands of pegmatite \& quartz. These are medium to high grade, crystalline, medium to coarse grained metamorphosed rocks with well-developed foliation and gneissosity. The general foliation of the strata trend in N100$600 \mathrm{E}$ to S100-600W and dips at $100-400 / \mathrm{N} 1000-1500$. At places, rock exhibits tight ' $S$ ' shape folds and broad warps as evidenced from the swing in foliation. The rocks had undergone polyphase deformations leading to development of numerous tectonic dislocations, mega shears, discontinuities of different orders. In Dam complex, the rocks comprising quartz-biotite gneiss with small schistose bands, thin quartz veins and very small pegmatite bands are exposed. Eight sets of joint are recorded, amongst these five sets of joints are prominent and others are occasional or random joints [3]. Table. Igives the details of the prominent joints recorded in the study area.

TABLE I. DETAILS OF ThE JOINTS

\begin{tabular}{|l|l|l|l|l|l|}
\hline $\begin{array}{l}\text { Joint } \\
\text { No. }\end{array}$ & $\begin{array}{l}\text { Dip } \\
\text { amount }\end{array}$ & $\begin{array}{l}\text { Dip } \\
\text { direction }\end{array}$ & $\begin{array}{l}\text { Spacing } \\
\text { (in cm) }\end{array}$ & $\begin{array}{l}\text { Conti- } \\
\text { nuity } \\
\text { (in m) }\end{array}$ & $\begin{array}{l}\text { Opening } \\
\text { (in cm) }\end{array}$ \\
\hline $\mathbf{J}_{\mathbf{1}}$ & $15^{\circ}-25^{\circ}$ & $\begin{array}{c}\mathrm{N} 060^{\circ}- \\
110^{\circ}\end{array}$ & $02-80$ & $\begin{array}{l}\text { Longer, } \\
>20\end{array}$ & $\begin{array}{l}\text { Tight, } \\
\text { Foliation }\end{array}$ \\
\hline $\mathbf{J}_{\mathbf{2}}$ & $65^{\circ}-70^{\circ}$ & $\begin{array}{c}\mathrm{N} 230^{\circ}- \\
260^{\circ}\end{array}$ & $05-50$ & $\begin{array}{l}01-08, \\
\text { Broken } \\
+15\end{array}$ & $01-05$ \\
\hline $\mathbf{J}_{3}$ & $40^{\circ}-60^{\circ}$ & $\begin{array}{c}\mathrm{N} 190^{\circ}- \\
220^{\circ}\end{array}$ & $25-100$ & $01-05$ & $10-100$ \\
\hline $\mathbf{J}_{\mathbf{4}}$ & $50^{\circ}-75^{\circ}$ & $\begin{array}{c}\mathrm{N} 340^{\circ}- \\
015^{\circ}\end{array}$ & $10-20$ & $\begin{array}{l}02-06, \\
\text { Broken } \\
+15\end{array}$ & $01-10$ \\
\hline $\mathbf{J}_{5}$ & $35^{\circ}-65^{\circ}$ & $\begin{array}{c}\mathrm{N} 300^{\circ}- \\
315^{\circ}\end{array}$ & $15-150$ & $01-05$ & $01-30$ \\
\hline $\mathbf{J}_{\mathbf{6}}$ & $50^{\circ}-60^{\circ}$ & $\begin{array}{c}\mathrm{N} 045^{\circ}- \\
060^{\circ}\end{array}$ & Random & $50-200$ & Tight \\
\hline $\mathbf{J}_{7}$ & $65^{\circ}-80^{\circ}$ & $\begin{array}{c}\mathrm{N} 355^{\circ}- \\
345^{\circ}\end{array}$ & Random & $100-200$ & Tight \\
\hline $\mathbf{J}_{\mathbf{8}}$ & $45^{\circ}-60^{\circ}$ & $\begin{array}{c}\mathrm{N} 155^{\circ}- \\
165^{\circ}\end{array}$ & $\begin{array}{l}\text { Occassio } \\
\text {-nal }\end{array}$ & $50-200$ & Tight \\
\hline
\end{tabular}

III. GEOTECHNICAL INVESTIGATIONS AND EVALUATION OF ROCK MASS CONDITIONS

A proper understanding about the river valley or bed rock profile, surface \& sub-surface geological condition and subsurface hydrological condition is very important for planning and successful execution of the works. To evaluate the rock mass condition at the site, a detailed geotechnical investigation programme was formulated, which includes

- Topographical survey of the area around coffer dam axis

- Surface geological mapping of the exposures and overburden in the upstream coffer dam area

- Exploratory borehole drilling in stages

- Systematic drill core logging of the boreholes

- Preparation and updation of geological sections

The survey work and surface geological mapping helped in knowing the river valley profile and disposition of overburden and rocky outcrops, which ultimately helped in borehole planning and their positioning. The river valley at dam site is characterized by steep rocky cliffs on the left bank and gentle abutments on the right bank, exposing medium to coarse grained, moderately jointed and blocky quartz rich biotite gneiss as a bed rock. It was inferred that the left bank topography is controlled by valley ward dipping steep and continuous striking master joints, whereas that of right bank is controlled by gentle to moderate dipping foliation joints[5].

To explore the subsurface bedrock profile, seven boreholes of different depths were drilled along or adjacent to the axis of the upstream coffer dam in stage-I. Out of seven boreholes, four holes were planned as vertical and three as inclined at varied angles depending upon the topography and assumed subsurface bed rock profile. Table II gives the summarized account of the boreholes drilled.

Systematic core logging of the exploratory drill holes was done to evaluate the rock mass condition and to establish the fresh bed rock level, which revealed that the presence of thick colluvium/hill wash material consisting of rocky boulders, cobbles and gravels set in overburden soil (Silty and sandy matrix) with intermediate zones of RBM in the river bed and 20 - 25m wide zone of RBM below El 1125m, comprising of sandy layers and well-polished pebbles of gneiss, quartzite and leucogranite, located towards left edge of the present course of the river. This thick RBM zone represents a buried channel developed due to deposition of riverine material along the old course of the river. Due to presence of thick colluvium underlain by deep buried channel, the deepest level of the bed rock was found at El $1100 \mathrm{~m}$, i. e about $87 \mathrm{~m}$ deeper from top of the coffer dam (El 1187m). However, it was again lowered to some extent to fresh and foundation grade rock during actual excavation for construction of $\mathrm{COW}$, where maximum depth of foundation grade rock was found to be $92.90 \mathrm{~m}$ in two adjacent panels of the wall. Fig.2 represents the geological section along upstream coffer dam axis showing disposition of overburden material and bed rock profile across the valley [5] 
The colluvial debris are regarded as product of rock destruction, fallen from rocky outcrops and accumulated at the toe of the hill under the force of gravity. The rocky boulders were of medium to coarse grained quartzo-feldspathic gneiss, quartzite and leucogranite. The majority of were of quartzo feldspathic gneiss, which ranges from very small to maximum

TABLE II. SUMMARY OF BORE HOLES

\begin{tabular}{|l|l|l|l|l|l|}
\hline $\begin{array}{l}\text { Borehole } \\
\text { No. }\end{array}$ & Location & $\begin{array}{l}\text { Collar } \\
\text { Eleva- } \\
\text { tion in } \\
\text { m }\end{array}$ & $\begin{array}{l}\text { Inclina- } \\
\text { tion }\end{array}$ & $\begin{array}{l}\text { Depth } \\
\text { of hole } \\
\text { in m }\end{array}$ & $\begin{array}{l}\text { Bedrock } \\
\text { Depth } \\
\text { in m }\end{array}$ \\
\hline CDH-1* & Right Bank & 1184 & Vertical & 83.6 & 47.8 \\
\hline CDH-2 & Right Bank & 1188 & Vertical & 54.0 & 41.0 \\
\hline CDH-3 & Left Bank & 1176 & $60^{0}$ & 111.0 & 75.0 \\
\hline CDH-4 & Left Bank & 1176 & $60^{0}$ & 62.8 & 35.5 \\
\hline CDH-5 & Right Bank & 1176 & $70^{0}$ & 69.0 & 58.5 \\
\hline CDH-6 & Right Bank & 1205 & Vertical & 42.0 & 29.6 \\
\hline CDH-38* & Right Bank & 1195 & Vertical & 60.0 & 35.0 \\
\hline
\end{tabular}

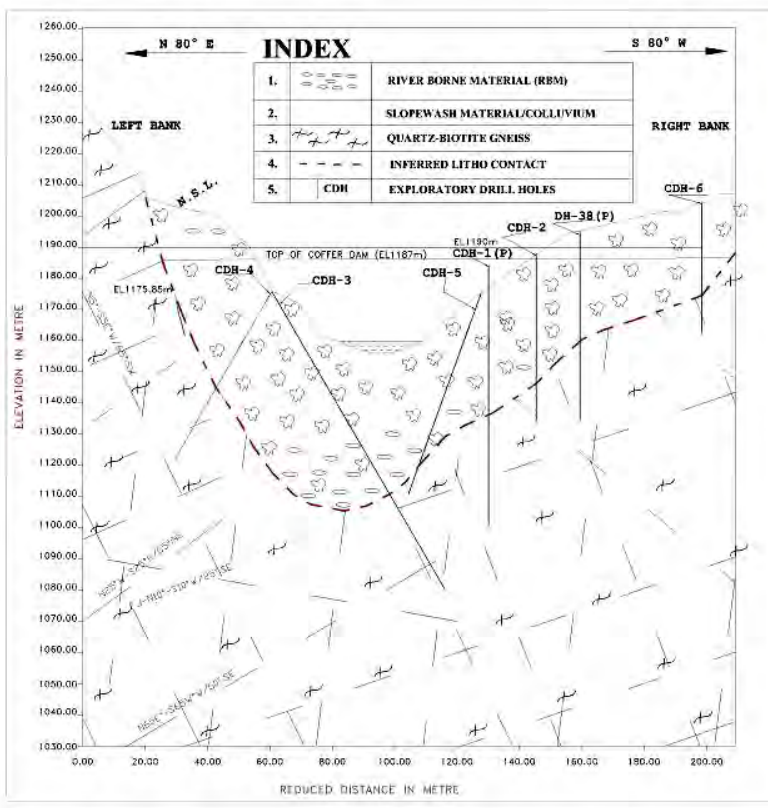

Fig.2. Geological section along coffer dam axis

up to $15 \mathrm{~m}$ in size, whereas the boulders of quartzite and leucogranite were of small to medium size. As the material is not transported from long distance, generally most of the boulders were angular in shape. The overburden soil is light yellowish to light brownish coloured, granular from very fine to medium grained. It is the matrix of silt, sand and fine gravels but the major part of the soil is silty. The average percentage of rocky boulders in soil matrix ranged from $30 \%$ to $40 \%$. Profuse fracturing and alteration along the joints in the drill cores on the right abutment strongly suggested the presence of a shear zone running slightly askew to the River channel in this area. Considering the fair rock quality designation (RQD), joints disposition and rock mass condition of the bed rock observed in the drill core, it was inferred that a fair quality of rockmass with ' $Q$ ' value ranging from 4 to 8 would be available at the deepest foundation level. However the rockmass classification from the study of drill cores has got its own limitations, the actual rockmass condition is conclusively established only after excavation and exposing the foundation grade rock mass [5].

The geological mapping, exploration, borehole logging and geological sections provided high level of confidence in understanding the surface and subsurface rock mass condition and delineating the subsurface zones of different hydraulic conductivity, which ultimately helped in proper planning \& developing safe design and successful excavation \& construction of plastic concrete COW.

\section{Construction of Plastic Concrete Cutoff Wall}

The data collected from geotechnical investigations presented some serious issues like -

- Wide and irregular river valley profile

- Bed rock at high depth $( \pm 90 \mathrm{~m})$ from the top level of the coffer dam.

- Complex geological condition and variety of overburden material in abundance

- Big size and high percentage of rocky boulders in the overburden material

The occurrence of variety of overburden material in the valley and that to for considerable depth, led to the concerns regarding seepage or leakage of the water and potential piping beneath the dam seat. This felt the necessity to have a provision of diaphragm in dam body design to encounter the leakage problem and reduce the risk factor. Now days plastic concrete cut off walls are seen as best possible solutions to reduce the risk of these problems. The plastic concrete is a mixture of aggregates, cement, and water and bentonite clay with high water/cement ratio. Such a cut-off wall must be resistant when subjected to earthquake loading. This requires that the wall be adequately deformable and plastic concrete is considered as an appropriate material providing such deformability [2]. Hence, $132 \mathrm{~m}$ long, $1.2 \mathrm{~m}$ thick plastic concrete Cut-off Wall (COW) extended up to the bed rock was provided in the center of upstream coffer dam of Punatsangchhu-1 hydropower project.

The construction of wall was commenced in April 2012 and was completed in December 2012. The entire work of excavation and construction of $\mathrm{COW}$ was executed by $\mathrm{M} / \mathrm{s}$ Bauer Foundations; Germany under the supervision of $\mathrm{M} / \mathrm{s}$. L \& $\mathrm{T}$ Constructions (Contractor) and Punatsangchuu-1 Hydropower Authority (Main executing body). The trench was excavated from ground level by using combination of conventional grab and hydraulic trench cutter. A chisel was used for breaking of large and high strength rock boulders. The equipments and materials that were used for construction of COW are.

\section{A. Equipments}

- Cut off wall Trench Cutter on carrier crane - 2 Nos.

- Grab on carrier crane - 1 Nos.

- Chisel on carrier crane - 1 Nos. 
- BE 250 de-sanding units-2 for cutters and 01 in spare Bentonite mixer- 1 working and 01 in spares

- Habermann KPKT slurry pump of 400 cum/hr capacity for cutter

- Feeding pumps- 2 Nos.

- Pipeline system for bentonite handling, circulation and storage- 1 Nos.

\section{B. Materials}

- Bentonite - Slurry gel for trenching \& Pilo gel for Plastic concrete

- TAM Pipe with manchette for pre-treatment works

- Cement - PPC

- Aggregates

- Water

A view of the grab \& trench cutter is shown in Fig. 3 and general view of COW excavation operation in Fig. 4.

\section{Methodology}

Prior to actual excavation and construction of COW, some preparatory works are needed, which includes construction of working platforms, ramps, guide walls and pre-treatment or strengthening works [4].

1) Working platforms and ramps: The working platform were designed and built on 2 levels including ramp connections in order to move safely the crawler mounted equipment of capacity up to 250 tons and concrete trucks. They were leveled firmly and maintained all the time to ensure a safe operation. Ramp inclination was kept at maximum $8^{\circ}(14 \%)$. Temporary slopes were kept at an inclination of 1:1.5 without stabilization and 1:1 with stabilization (colcrete, boulders).

2) Guide walls: Guide walls were constructed prior to the cutoff wall construction in order to provide:

- Guidance to ensure the correct alignment of the COW.

- Protection against instability of the top soil zone of the trench caused by fluctuating bentonite levels and agitation of the slurry during excavation.

- Support for the trench stability at the top zone, affected by the vertical surcharge weight of the trench cutter and other heavy jobsite machineries adjacent to the trench.

The reinforced concrete guide wall (with typical L-shape section) was constructed, keeping its top at lower level than the working platform to limit bentonite or concrete spill during operation. Further, inside the guide wall, solid wooden horizontal bracings were installed at every $2 \mathrm{~m}$ interval to avoid displacement of the guide wall when working with heavy construction equipment next to the open trench. The gap between the 2 guide walls was backfilled with proper noncohesive material like gravel or sand, to avoid overconsumption of bentonite or concrete, when excavating or casting concrete in neighbour panels. Fig.5 shows typical Lshape section of guide wall and Fig.6 shows the view of guide walls and wooden bracings.

3) Pre-treatment: In order to enable a safe and continuous

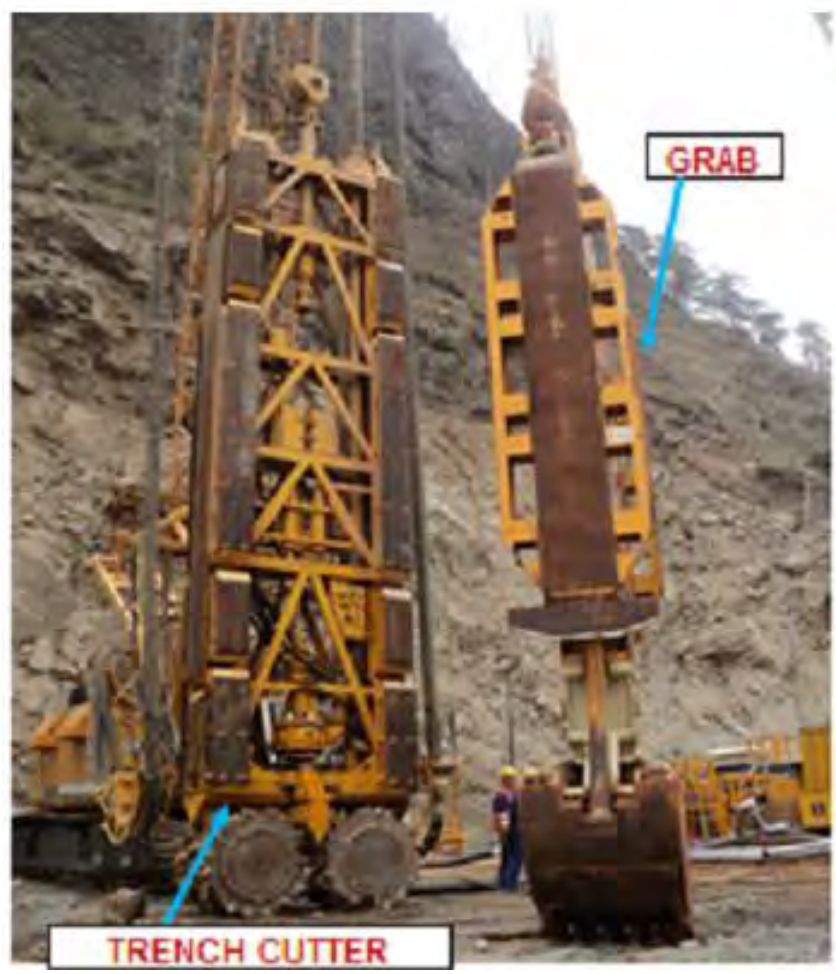

Fig. 3. A view of hydraulic trench cutter and grab

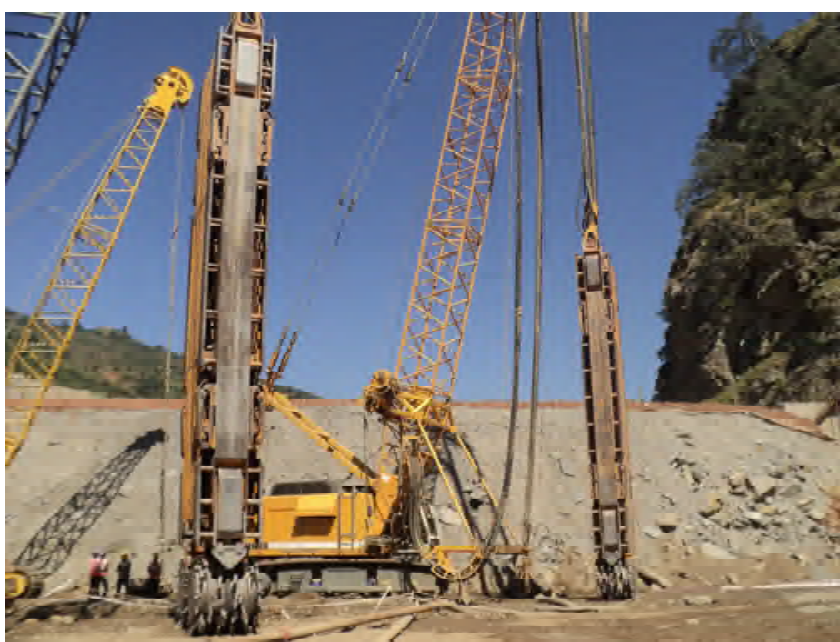

Fig. 4. A view of COW excavation operation

COW operation the stabilization of soil along the dam axis and mitigation of water paths within the vicinity of the cut off wall needs to be done by Pre-Treatment. This was achieved by 'grouting under gravity' and 'Tam grouting by pressure injection'. The purpose of the grouting works by gravity was to reduce losses of the Bentonite slurry from cut- off panels and to avoid surprises in consumption of material and time, when applying pressure grouting by TAM method. The purpose of Tam grouting by pressure injection was to fill the 
voids and macro cracks existing in the decomposed rock and in the overlain fill, alluvium and colluvium. The general idea of both grouting methods is to fill cracks and fissures, gaps to

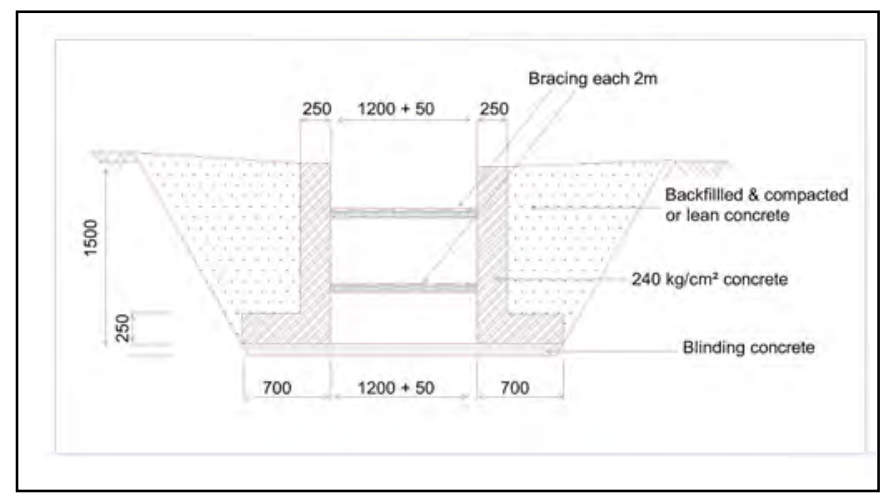

Fig.5. A typical L-shape section of guide wall

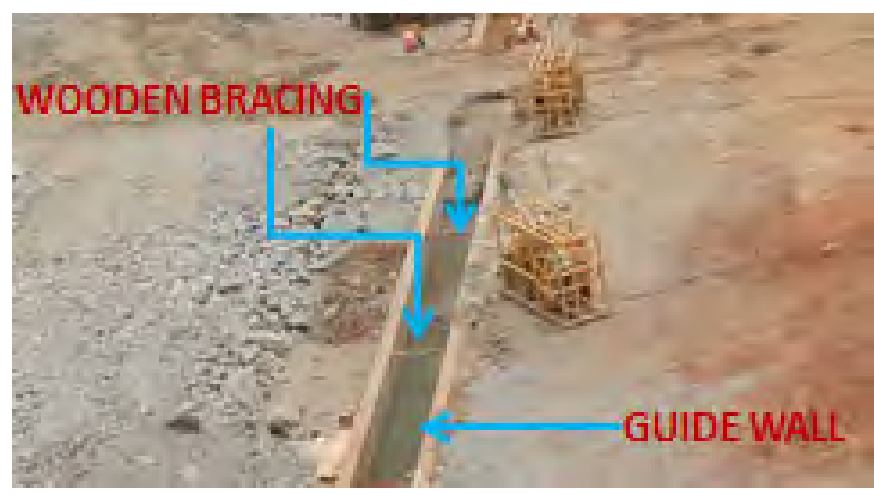

Fig.6. A view of guide wall with wooden bracings

stabilize big stones/boulders in the matrix of the over burden soil to avoid collapse of boulders.

4) Panel excavation and concreting: The typical Cut-off Wall panel excavation through the overburden soils and/or clay core was accomplished by using a combination of conventional/hydraulic trench cutter and grab. The trench cutter was used for excavation to the designed final depth and the over-cutting of adjacent (primary) panels. Crawler mounted cranes for chisel operation were used, when obstacles have to be removed or cutting performance required with support by application of chisel. The entire wall of about $132 \mathrm{~m}$ length was constructed across the river by excavating 55 panels in alternating sequence. The excavation was done stage wise in different panels as primary and secondary. The primary panels consisted of 3 bites for combined length of $6 \mathrm{~m}$, with each panel having length of 2 to $2.2 \mathrm{~m}$.

During excavation, the sides of the excavated trench were supported by bentonite slurry. Additionally the suspension was also used for transporting the excavated material out of the panels when working with the trench cutter. During the excavation process the level of the bentonite slurry within the excavated trench was continuously monitored and checked to ensure stability of the open trench. While cutting, the level of slurry was maintained at not lower than $0.5 \mathrm{~m}$ below top of guide wall. While grabbing or casting concrete, it was maintained at not lower than $1.5 \mathrm{~m}$ below top of guide wall or depending on the actual river level/ groundwater situation.

After completion of excavation for panels the plastic concrete was pumped into the trench with pressure. As the concrete level rises during placement in the trench, the excess bentonite is drawn off and pumped to the plant station for re use [1]. After construction of a couple of primary panels, the intermediate secondary panels were excavated. The secondary panels were excavated by cutting in between two adjacent primary panels with $40 \mathrm{~cm}$ overlapping with side panels, thus having total length of each secondary panel as $2.8 \mathrm{~m}$. For this purpose the BC 40 trench cutter with its frame width of $2.8 \mathrm{~m}$ was used, which cut into the plastic concrete of the two adjacent primary panels resulting in a rough grooved surface in the cast primary panel further ensuring a higher quality joint between panels. Fig. 7 shows the layout plan of primary and secondary panels of COW

The overcutting was carried out not before the minimum concrete strength of at least $0.5 \mathrm{MPa}$ was attained, which is common practice in cut-off wall construction. The required curing period for the approved mix design was verified on site in trial mixes carried out prior to execution. Generally a curing period of 3 days is expected before secondary panels are going to be excavated between primary panels [4].

Concrete was supplied to the trench locations by concrete trucks $\left(6 \mathrm{~m}^{3}\right.$ capacity each) at a rate sufficient to ensure a minimum pouring rate of about $60 \mathrm{~m}^{3}$ per hour via tremie pipe. Prior to commencement of each pour a MS flap was provided at the bottom of hopper and plastic concrete was poured through hopper/pipes to hinder mixing and concrete segregation. One tremie pipe (diameter $250 \mathrm{~mm}$ ) per trench $(2.8 \mathrm{~m})$ was installed by a service crane. The plastic concrete was poured directly from the truck mixer into the hopper of the tremie pipe string. During concreting the tremie pipe was kept continuously immersed in the fresh concrete by a minimum of 2 meters. While the concrete is rising from bottom to top, sections of the tremie pipe string was taken out to fulfill the requirement of a minimum $2 \mathrm{~m}$ embedment of the bottom of the string into fresh concrete on one side and to ensure constant flow of fresh concrete on the other side.

5) Verticality and integrity of wall: Theoretically, the cut off wall is required to be continuous and properly aligned with designed thickness. Any misalignment of panels due to varied geological conditions may cause defects in the wall thus allowing piping or leakage to occur. Hence careful control regarding the verticality of each panel is essentialy required.

During initial excavation, the guide walls were constructed to control and guide the trench cutter and grab and to ensure the alignment and verticality of panels. Also, the verticality was controlled by an in-built electronic inclinometer (B-Tronic), which measures the deviation of cutter in two directions. Any such deviation displayed on the computer monitor installed in the operator's cabin was noted and accordingly the cutters were steered during excavation to compensate any drift in verticality. In addition, a "KODEN" measuring device was used to check the verticality of each panel after excavation. It is an ultrasonic measuring device capable of measuring verticality of panels in both directions 
by using ultrasonic probe lowered into the trench. The combination of guide wall, B-Tronic and Koden devices helped in careful examination of appropriate overlapping of panels, maintaining the verticality of the wall and successful execution of the work.

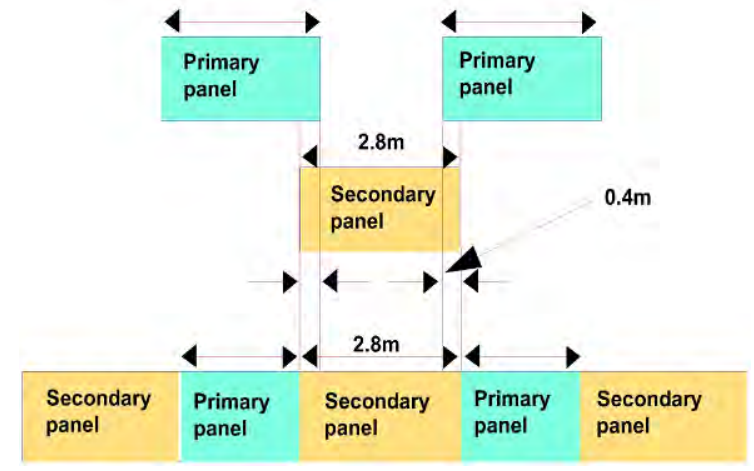

Fig.7. Layout plan of primary and secondary panels of COW

6) Concrete properties and mix design: Fresh and hardened plastic concrete needs to have certain properties. A fresh concrete has to have

- Sufficient flow ability in terms of slump (in the range of $220+/-30 \mathrm{~mm}$ )

- Adequate stability with respect to bleeding, segregation and water losses by filtration

- Ample duration of workability considering the time frame needed for the casting of subsequent concrete batches.

The technical specifications for hardened plastic concrete considered as per design are as under

- Unconfined compressive strength between 2 to $4 \mathrm{MPa}$ after 28 days.

- Low permeability (<01 Lugeon)

- Ductile stress-strain properties to accommodate differential stresses and deformation without cracking.

Based on the aforesaid requirements a typical mix design as given below was chosen for construction of plastic concrete COW, after several trial mixes-

- $\quad$ Cementitious material $=200-220 \mathrm{~kg}$

- Bentonite $($ Pilo Gel $)=25-40 \mathrm{~kg}$

- $\operatorname{Aggregates}(0-10 \mathrm{~mm})=1650-1700 \mathrm{~kg}$

- Water: Cement ratio $=2.0$ to 2.5

7) Founding and confirmation of depth of panels: It is very essential to ensure and confirm that no seepage path is left beneath the wall. Hence, it is critical aspect of the wall to ensure that base of all the panels of wall are sufficiently embedded in slightly weathered to fresh in-situ rock. It needs special arrangements at desander plant to collect the rock samples of that depth. The arrangements at de-sanding plant were made in such a way that the samples could be taken by placing an excavator bucket beneath the discharge point for larger cuttings collected from the assumed depth. This enabled to collect high quality rock samples, which were always observed and checked by the author being the resident geologist of the project for confirmation of arrival of fresh insitu rock. Based on my recommendations and suggestions the excavation was continued further or discontinued so that the panel is extended for $0.60 \mathrm{~m}$ into the foundation grade rock for sufficient socketing. The minimum and maximum depths of the panels as excavated were as $14.80 \mathrm{~m}$ (Panel No. P-1) on left bank and 92.90m (Panel Nos. P-21 \& S-22) in the center of COW respectively.

. TABle III Summary OF PANEL DePTH

\begin{tabular}{|l|l|l|l|l|c|}
\hline $\begin{array}{c}\text { Panel } \\
\text { No. }\end{array}$ & $\begin{array}{c}\text { Depth } \\
\text { in m }\end{array}$ & $\begin{array}{c}\text { Bottom } \\
\text { Elevation } \\
\text { in m }\end{array}$ & $\begin{array}{c}\text { Panel } \\
\text { No. }\end{array}$ & $\begin{array}{c}\text { Depth } \\
\text { in m }\end{array}$ & $\begin{array}{c}\text { Bottom } \\
\text { Elevation } \\
\text { in m }\end{array}$ \\
\hline P-1 & 14.80 & 1161.05 & P-29 & 67.90 & 1107.95 \\
\hline S-2 & 22.00 & 1153.85 & S-30 & 62.80 & 1103.05 \\
\hline P-3 & 25.20 & 1150.60 & P-31 & 59.00 & 1116.85 \\
\hline S-4 & 35.20 & 1140.65 & S-32 & 57.80 & 1118.05 \\
\hline P-5 & 40.20 & 1135.65 & P-33 & 57.80 & 1118.25 \\
\hline S-6 & 57.60 & 1118.25 & S-34 & 58.20 & 1117.65 \\
\hline P-7 & 63.60 & 1111.95 & P-35 & 58.20 & 1117.65 \\
\hline S-8 & 64.90 & 1110.95 & S-36 & 56.00 & 1119.85 \\
\hline P-9 & 66.00 & 1109.85 & P-37 & 55.70 & 1120.15 \\
\hline S-10 & 66.80 & 1109.05 & S-38 & 52.80 & 1123.05 \\
\hline P-11 & 69.30 & 1106.55 & P-39 & 51.60 & 1124.25 \\
\hline S-12 & 73.30 & 1102.55 & S-40 & 51.30 & 1124.55 \\
\hline P-13 & 76.30 & 1099.55 & P-41 & 51.30 & 1124.55 \\
\hline S-14 & 77.90 & 1097.95 & S-42 & 49.60 & 1126.25 \\
\hline P-15 & 82.30 & 1093.55 & P-43 & 45.90 & 1129.95 \\
\hline S-16 & 85.30 & 1090.55 & S-44 & 36.60 & 1139.25 \\
\hline P-17 & 87.70 & 1088.15 & P-45 & 35.10 & 1140.75 \\
\hline S-18 & 88.80 & 1087.05 & S-46 & 48.95 & 1141.05 \\
\hline P-19 & 90.20 & 1085.65 & P-47 & 47.80 & 1142.20 \\
\hline S-20 & 91.60 & 1084.25 & S-48 & 46.90 & 1143.10 \\
\hline P-21 & 92.90 & 1082.95 & P-49 & 44.90 & 1145.10 \\
\hline S-22 & 92.90 & 1082.95 & S-50 & 44.40 & 1145.60 \\
\hline P-23 & 92.70 & 1083.15 & P-51 & 42.80 & 1147.20 \\
\hline S-24 & 92.30 & 1083.55 & S-52 & 42.10 & 1147.90 \\
\hline P-25 & 83.70 & 1092.15 & P-53 & 39.60 & 1150.40 \\
\hline S-26 & 78.60 & 1097.75 & S-54 & 38.70 & 1131.30 \\
\hline P-27 & 72.90 & 1102.95 & P-55 & 36.90 & 1153.31 \\
\hline S-28 & 71.60 & 1104.25 & -- & -- & - \\
\hline & & & & & \\
\hline
\end{tabular}

During actual excavation of the COW, the bed rock profile as inferred from exploratory drilling and the actual foundation grade rock profile obtained after excavation of panels, varied to certain extent. Both the profiles did not show much difference on the right bank but it varied to great extent in the center and on left bank due to occurrence of sheared material

The author co-related both the profiles and tried to find the reasons for such variation. Based on the correlation and the collected rock samples at de-sander, it was found that the difference in actual depths of bed rock in both the profiles may not be much, but due to occurrence of shear zone at depth in the center of the valley the trenching/cutting was done up to acceptable foundation grade rock. The difference was due to presence of shear zone dipping gently towards valley, which was missed during stage-I drilling because of wider spacing crated at depth between drill holes $\mathrm{CDH}-3$ and $\mathrm{CDH}-4$ due to their opposite and comparatively gentler inclinations. Steeper inclination $\left(>70^{\circ}\right)$ of $\mathrm{CDH}-3$ could have given the better profile. It was missed as drill holes being the point data but 


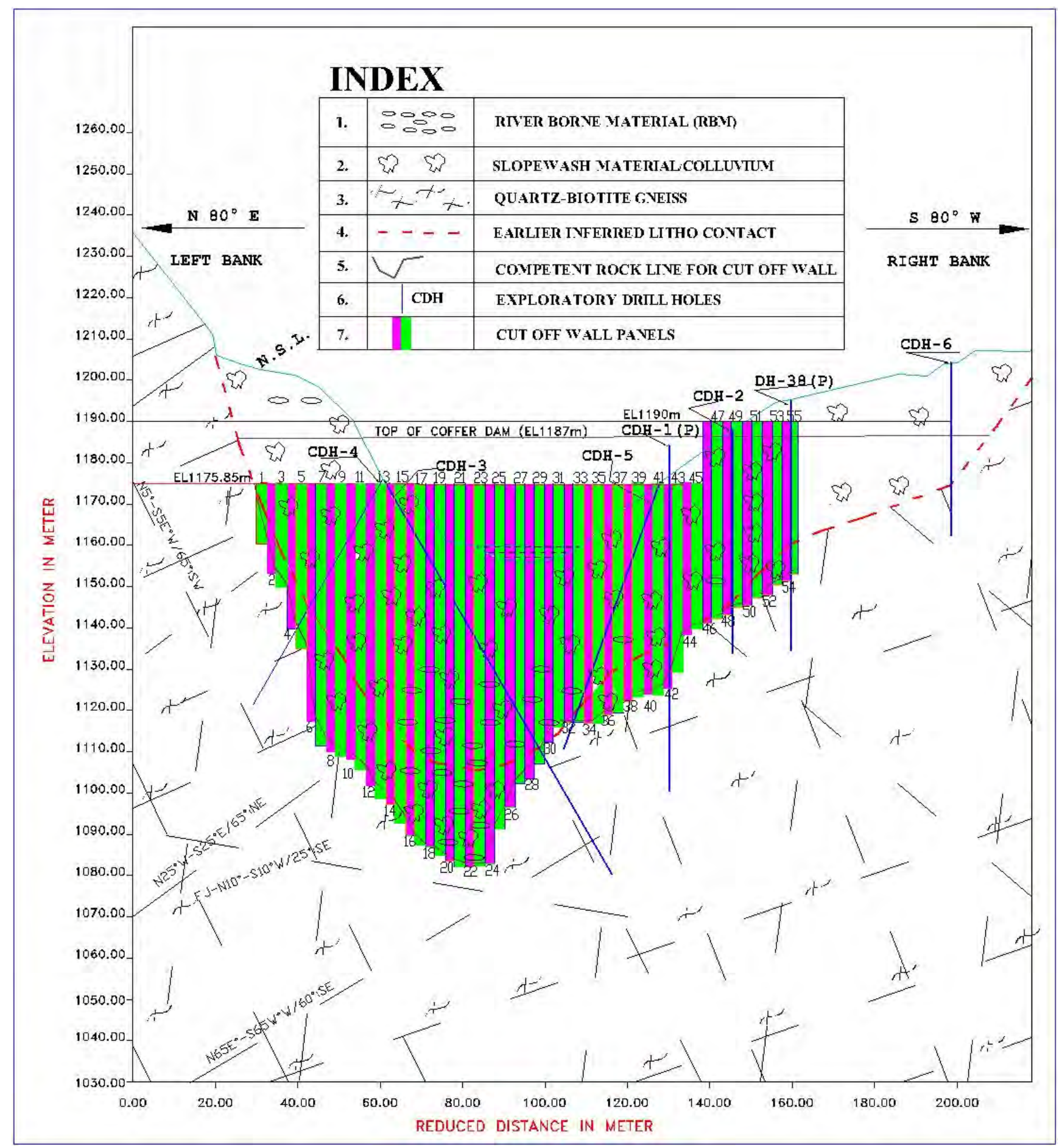

Fig.8 Showing COW Panels and inferred and actual fresh rock profiles

was confirmed during the actual excavation for Table III gives the summary of actual depths achieved in each panel of COW and Fig. 8 shows COW panels and inferred bed rock $\&$ foundation grade rock profiles.

\section{CONCLUSION}

Irregular river valley profile, complex geological condition and variety of overburden material in abundance, bed rock at high depth, big size and high percentage of rocky boulders in the overburden material were the key geological adversities at Punatsangchhu-I hydropower project, Bhutan. Considering these facts, probability of seepage or leakage and potential for internal erosion and piping trough the upstream coffer dam were some of the major issues of this project. The project authorities, in consultations with engineers and geologists developed and successfully executed an innovative plan to provide $1.2 \mathrm{~m}$ 
thick plastic concrete Cut-off Wall up to bed rock as a best possible solution to encounter the referred problems.

The key factors for successful installation of the Cut-off Wall included sufficient embedment of the wall toe into sound bedrock, proper continuity of the entire wall, integrity and quality control of the materials, timely and concurrent monitoring of the work and good workmanship. This approach of proper monitoring, testing and quality control accurately defined the wall installation process. This approach helped in further investigations and implementing the corrections only when and where deviation from the process occurred and/or potential defects were detected by the quality control program. After successful construction of the Cut-off Wall, the excavation for main dam at $\pm 415 \mathrm{~m}$ downstream was undertaken and very minimal water discharge was noticed at foundation level of the main dam blocks and the work could be done without much hindrance indicating the successful construction of COW.

The construction of $132 \mathrm{~m}$ long and $93 \mathrm{~m}$ deep plastic concrete cut off wall is one of its own kinds in the geodynamically complex Himalayan region to reduce the risk of leakage/piping to the acceptable levels and key to the success was proper planning, the geotechnical investigations and risk reduction measures that were undertaken during both the design and construction stages, which has resulted in successful construction of COW panels to encounter/address the above mentioned geological adversities

\section{ACKNOWLEDGMENT}

The author is grateful to Sh. N. Kutumba Rao. Additional Director General and HOD, Geological Survey of India, Central Region, Nagpur for his kind approval and according permission to publish this paper. Sincere thanks are due to Mr. M.M Powar, Dy. Director General and Dr. M.S. Bodas, Director, GSI, Pune for moral boosting and technical guidance. The author would like to acknowledge the entire management of Punatsangchhu-I hydropower project, $\mathrm{M} / \mathrm{s} \mathrm{L} \& \mathrm{~T}$ Constructions and $\mathrm{M} / \mathrm{s}$ Bauer foundation, Germany for their kind co-operation and support rendered during execution of the work.

\section{REFERENCES}

[1] C. Lobo, W.F. Guthrei and R, Kacker "A Study on the Reuse of Plastic Concrete Using Extended Set-Retarding Admixtures" Journal of Research of the National Institute of Standards and Technology, Volume 100, Number 5, September-October 1995.

[2] M. Ghazavi, Z. Safarzadeh and H. Hashemolhoseini "Response of plastic concrete Cut-off Walls in earth dams to seismic loading using finite element methods," 13th World Conference on Earthquake Engineering Vancouver, B.C., Canada, August 1-6, 2004.

[3] P. Gajbhiye "Geotechnical note on the rock mass condition and grouting in upstream coffer dam foundation" Unpublished report, January 2012

[4] S. O'Brien, C. Dann, G. Hunter and M. Schwermer "Construction of plastic concrete Cut-off Wall at Hinze dam" Published in ANCOLD proceedings of technical groups.

[5] T. Ghoshal and P. Gajbhiye "Geotechnical investigation of new dam complex, Punatsangchhu -I hydroelectric project, Bhutan, Unpublished report of Geological Survey of India, January 2009 